\title{
OPEN FRACTURES IN THE HAND
}

\author{
P. S. London, M.B.E., F.R.C.S. \\ Surgeon, The Birmingham Accident Hospital
}

These injuries vary a good deal in their type and how they are caused, but they have in common a serious effect on the form and function of the hand, and the special danger of sepsis.

\section{Main Types and Their Features \\ Fractures open from within}

A mild form occurs when the spike of a spiral fracture just pierces the skin. Much more destruction results when a large force acts across the fingers and causes the broken ends of bones to burst violently out to the surface (Fig. I). Nerves and vessels are liable to be disrupted, extensor tendons are more likely to be frayed or split than severed, and the tough, rounded flexors are often almost unscathed, though bared by the rending of their sheaths.

A fracture that deserves more care than it usually gets occurs in the finger tip (Fig. 2). It is open because the nail is torn out by the root, and because the closely attached nail bed is not amenable to suture sepsis is not unusual.

\section{Fractures open from without}

The most difficult to deal with are those due to crushing, which inflicts untidy and destructive wounds and multiple, often comminuted fractures. When they do not amputate, saws and axes cause fairly tidy injuries that are usually less difficult to treat. An occasional source of error is a dog-bite, which can sever a bone through quite a small wound (Fig. 3).

\section{Treatment}

The wound and the fracture cannot be regarded independently. The fracture needs a covering of skin to shield it from infection and the skin heals best over a stable frame of more or less normal shape. Apart from this, the need to retain as far as possible the differential mobility of closely packed structures of great delicacy, makes it essential to reduce distortion and scarring to a minimum. Internal fixation has much to offer to this end.

The following question should be answered before embarking on treatment.

\section{Is the digit worth saving?}

A single badly injured digit is often better

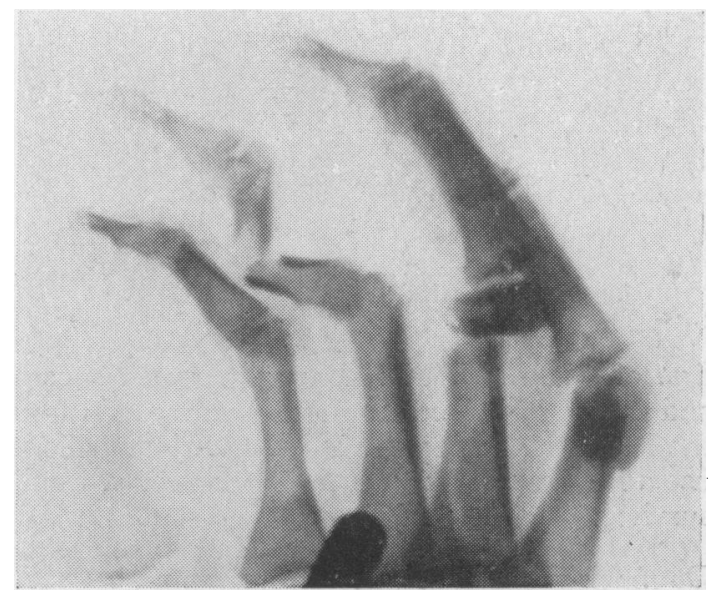

Fig. I.-Transverse fracturcs with severe local damage to the soft tissues.

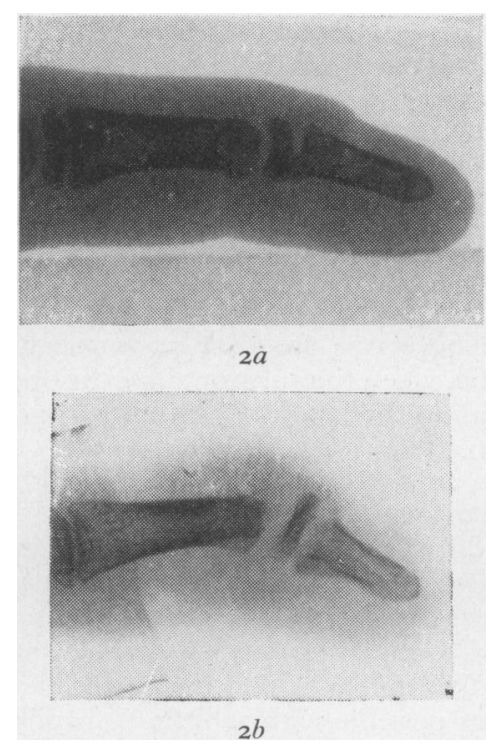

FIG. 2.-Displaced fracture of the finger tip with dislocation of the nail and septic complications.

amputated unless the patient forbids it. When more than one have been injured it is usually advisable to preserve all that appears viable at the 


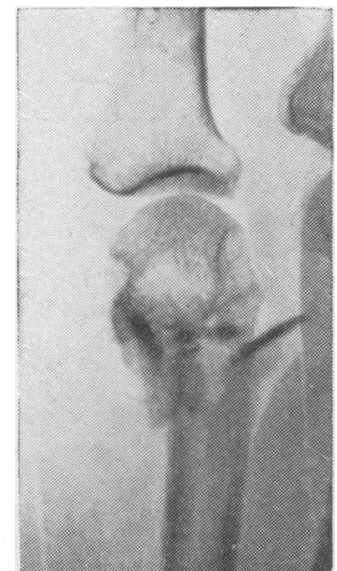

FIG. 3.-An unsuspected fracture due to a dog's bite.

first operation. The difference between success and failure may depend upon providing skin from the hand or elsewhere, but it is not justifiable to use a flap on a digit with little prospect of useful survival.

\section{Do the fractures need internal fixation?}

Apart from comminution, many fractures are unstable because of the disruption and stripping of the soft parts around them. Fixing a fracture enables these soft parts to heal in more or less natural disposition and without disturbance. Later attempts to correct deformity are liable to disrupt wounds or to increase internal scarring.

\section{Will skin grafts be needed?}

Unless the skin on the injured hand is likely to heal soundly on viable bone, joint, or tendon, it should be replaced by a suitable graft.

These questions are best answered under the anæsthetic, when the surgeon takes the opportunity of examining the hand by himself preparing it for operation.

\section{The influence of the surgeon}

The plan adopted must depend on the experience and skill of the surgeon. The expert may be able to undertake successfully the complete primary repair of formidable injuries, but juniors should content themselves with getting the hand healed as soon as possible with as little deformity as possible and in the simplest way possible. It is not enough to know the technical details of more elaborate measures; success is founded upon a careful apprenticeship in their application.

\section{The Wound and the Skin}

Dead and damaged tissue, dirt and loose fragments of bone must be removed and the remaining viable tissues closed by sutures or grafts.

Tidy wounds need little or no toilet before being closed, usually by simple suture.

Untidy wounds. When it is clear that a graft wille be needed, it may be advisable to remove more $\Rightarrow$ tissue than is obviously irrecoverable, rather than $\stackrel{\text { ? }}{+}$ hazard a flap in surroundings of doubtful viability. As far as possible, margins should be arranged $\overline{\bar{O}}$ where their scars will not hamper movement.

\section{Skin Grafts}

Split skin is the most generally useful, not only $\vec{O}$ for affording definitive closure of much of the hand's surface, but also for providing provisionale cover for parts that it is hoped to save althougho they are of doubtful viability. It takes well on alf living surfaces, except bare tendon, cartilage and $d_{t}$. cortical bone.

If a split skin graft is expected to survive, it should be thick, especially on palmar surfaces, otherwise thin.

Wolfe grafts are sometimes ideal, but are nevero essential.

Flaps may come from the hand itself or from $\overrightarrow{3}$ elsewhere (Fig. 4). The forearm and arm provide more suitable skin for the hand than do the chest $\vec{\oplus}$ and belly. Flaps should not be applied over tissugerso that are unlikely to survive.

On the hand itself, thenar and cross-digit flapiso are of great value, and both can be used ons different digits of the same hand. It should also beo noted that a digit destined for amputation can beo an invaluable source of skin for a fellow (Fig. 5)응

Tubed flaps have little place in primary treatment $\overrightarrow{\overrightarrow{0}}$

\section{The Fracture}

Some sort of splintage is almost always needed, if only to safeguard the soft parts. It may be externa! or internal.

\section{External Splintage}

This cannot be relied upon to hold unstable fractures in place (Figs. 6 and 7); it is liable to be cumbersome and to make X-ray films difficult to interpret.

Traction in Flexion is most useful for hinged on spiral fractures without much displacement. When the wounds need only small dressings, or haves healed, a single finger can be strapped over a roll of bandage in the palm, and made to point at the base of the thenar eminence; two or more cannot (Fig. 8). Strapping the finger to padded malleablø metal set in plaster is more cumbersome. It allows adjustment, but is not without its short-comings (Fig. 7).

Plaster of Paris is the least satisfactory externa禺 


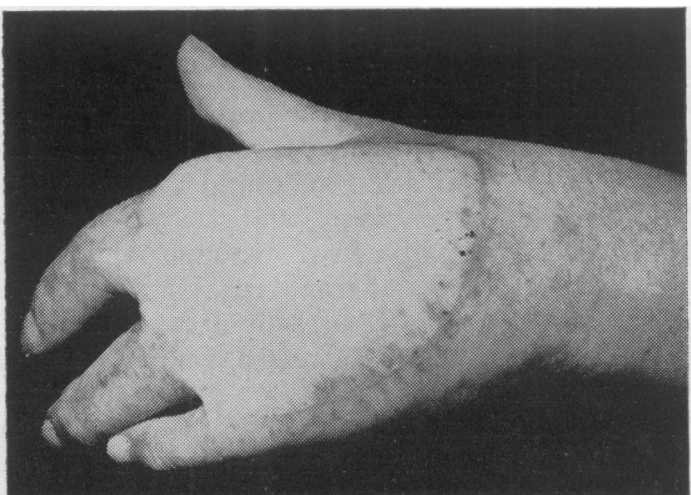

FIG. 4.-An abdominal flap (a) was necessary to cover the large raw area that included tendons and fractures $(b)$.

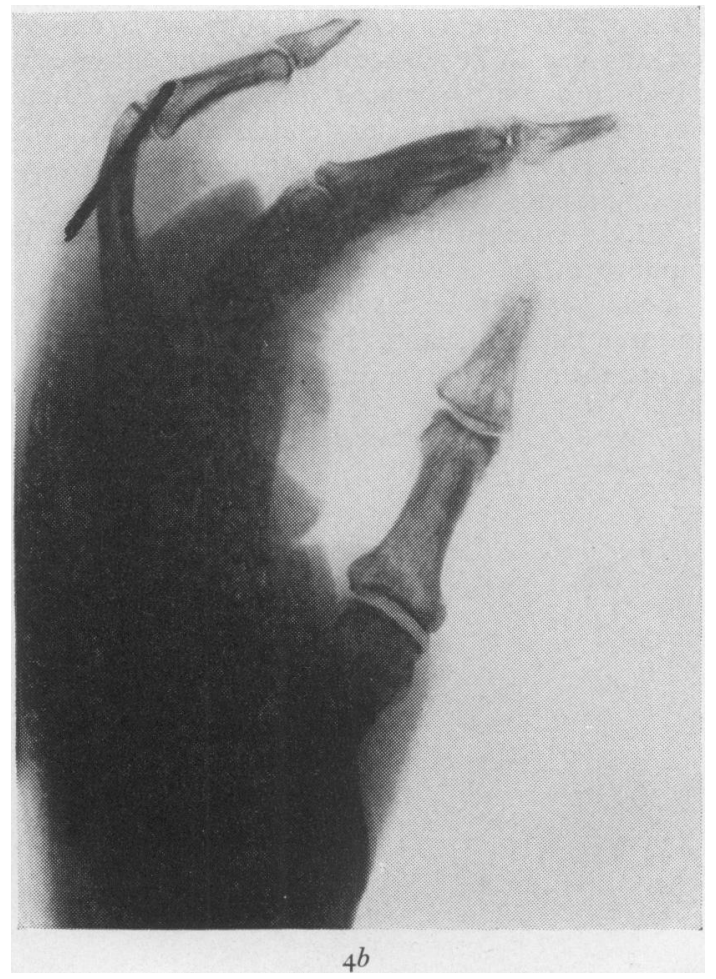

splint for the fingers, but can be successful with some metacarpal fractures.

'Boxing Glove' Splint. A ball of cotton wool, moistened with water or a flavine emulsion, can be moulded by a cotton bandage to conform accurately with the natural contours of the hand. As well as keeping the hand in a good positionthe metacarpophalangeal joints must be well flexed-when encased in dry wool and crêpe bandage it helps to prevent swelling. It is most

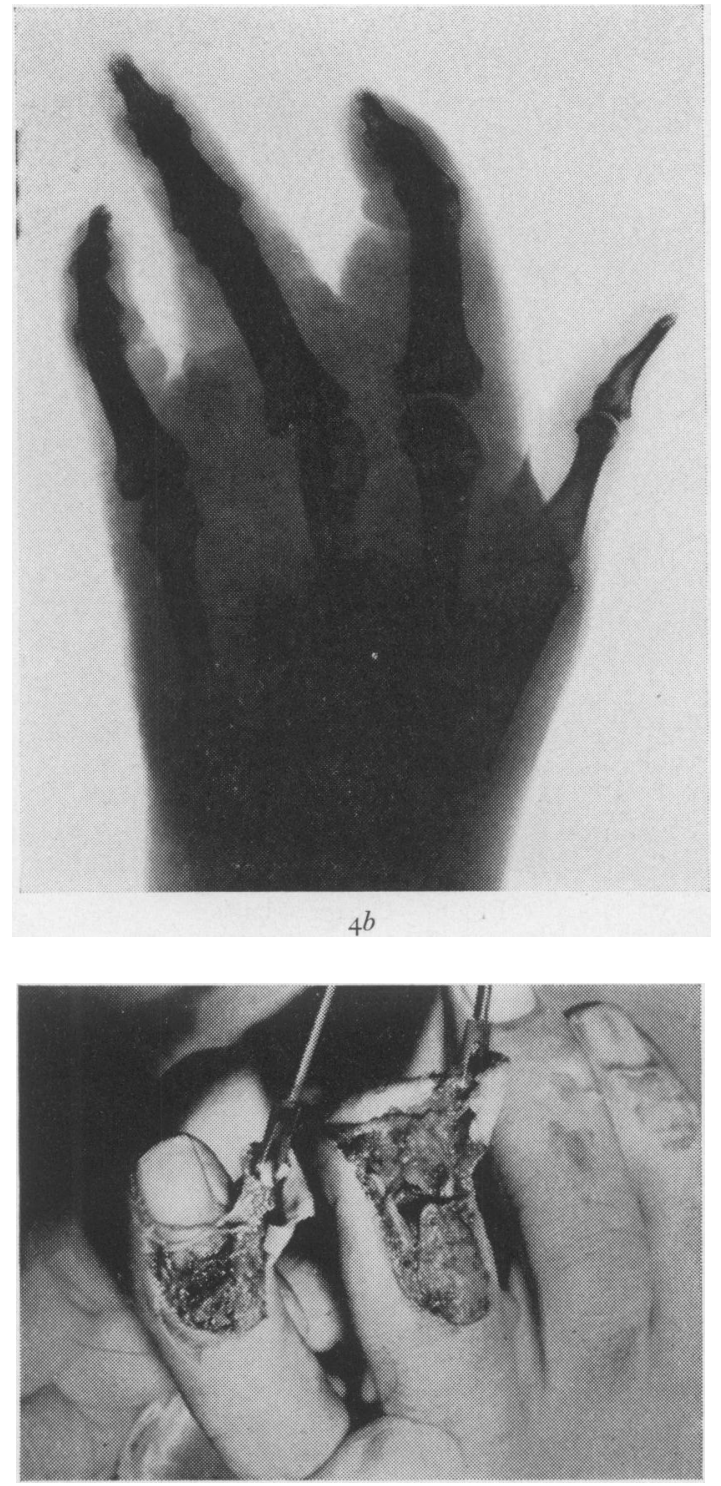

Fig. 5.-A small tubed flap restored the index finger without detriment to the remains of its neighbour.

suitable for fractures that do not need traction, although this can be incorporated in it.

Whatever method is used it is essential to confirm with $\mathrm{X}$-rays that the desired position has been achieved and maintained after any adjustment or change of dressing.

\section{Internal Fixation}

This has the great advantage of being less cumbersome and usually more reliable for unstable fractures than external splintage. Also, it may allow earlier use. 


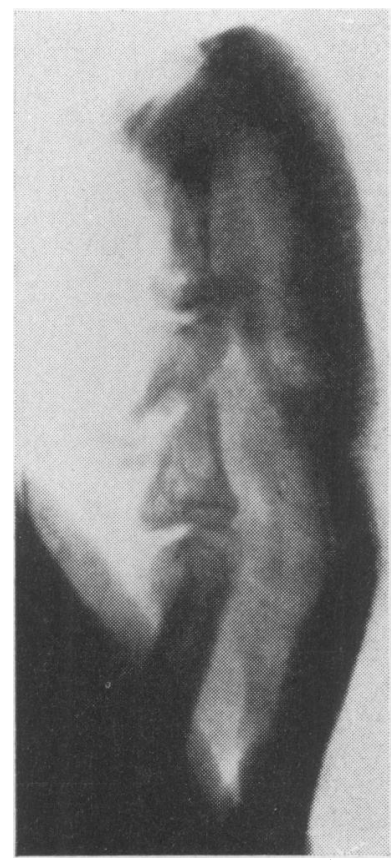

Fig. 6.-Plaster of Paris often does no more than support a fracture in deformity.
Kirschner wires can be used singly (Fig. 9) crossed, or in bundles (Fig. 4b). They are mose easily introduced through the broken end, pusheo on until the fracture can be reduced, and then pushed back to fix it. Single and crossed wires: should pierce cortical bone, and may be left pro jecting a few millimetres through the skinBecause this carries a small risk of sepsis, the entry points need to be carefully dressed until the wires are removed. The dense cortical bone of transverse fractures of phalanges and metacarpals takes at least six weeks to unite, but wires may be removed after a month if the fracture affect $\vec{\nabla}$ mainly cancellous bone.

Bundled wires can be made to fit tightly by filling the medullary space with them. They car be passed across the fracture one at at a time through a conveniently sited oblique entry hole, ois pushed into one end of the bone with enough sticking out to get a firm grip on the other end which is carefully levered into place over themin Because neither skin nor tendon is pierced, this method is less likely to cause stiffness and provides no way for infection to enter. Rush's nails provide unobtrusive strength of
support rather than fixity (Fig. 10).

Bone Pegs can be fashioned from the ulnar $8 \overrightarrow{\mathrm{k}}$ an amputated phalanx, but are liable to bre्gls before the fracture has united.

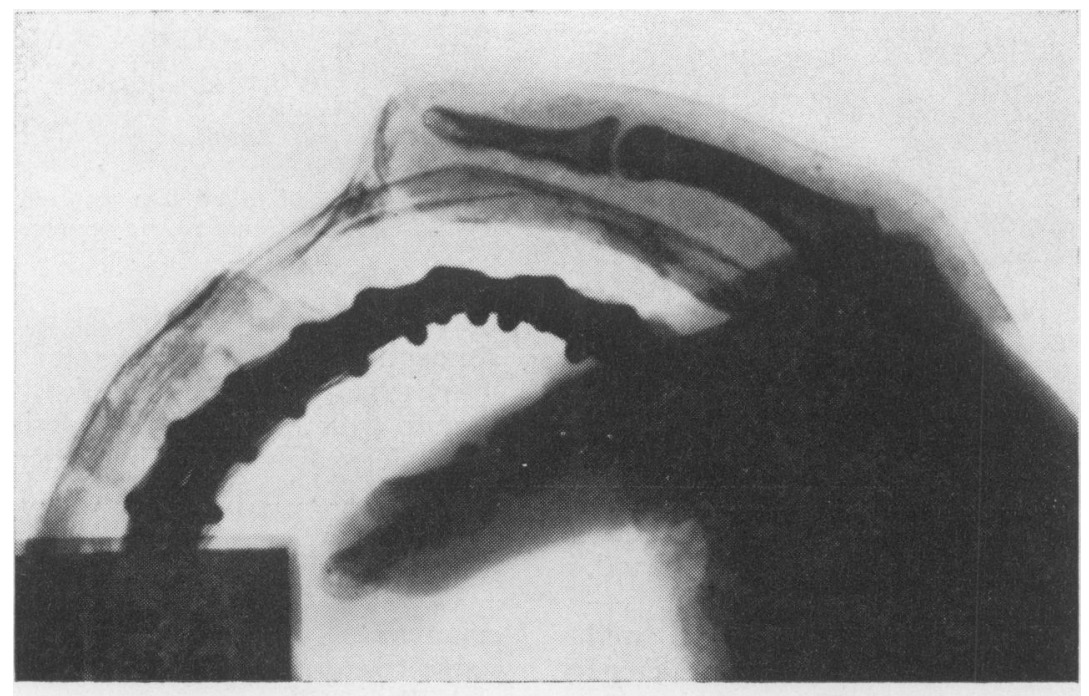




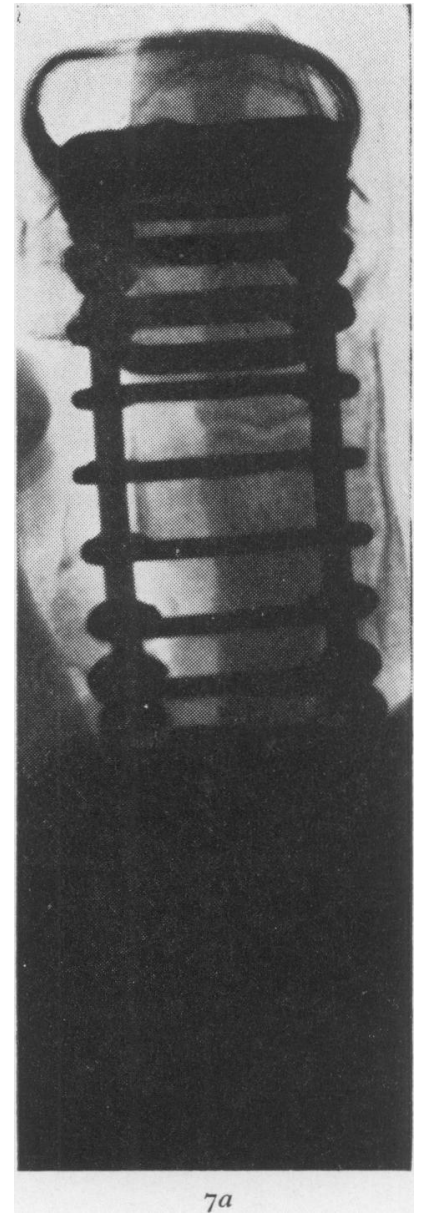

Wire Loops can be used successfully in pairs to encircle long spiral fractures, but soon work loose if passed through drill holes near a transverse fracture (Fig. 12).

Plates are not satisfactory unless specially designed for the hand.

\section{Special Problems}

Missing Bone. It is sometimes possible to maintain, by internal fixation, the general shape of the hand's skeleton and to fill the gaps with bone grafts later.

Smashed Bone in the finger tips (Fig. I I) should be removed and the viable skin closed comfortably over the remains.

Smashed foints that do not call for amputation should be treated by removing the articular surfaces

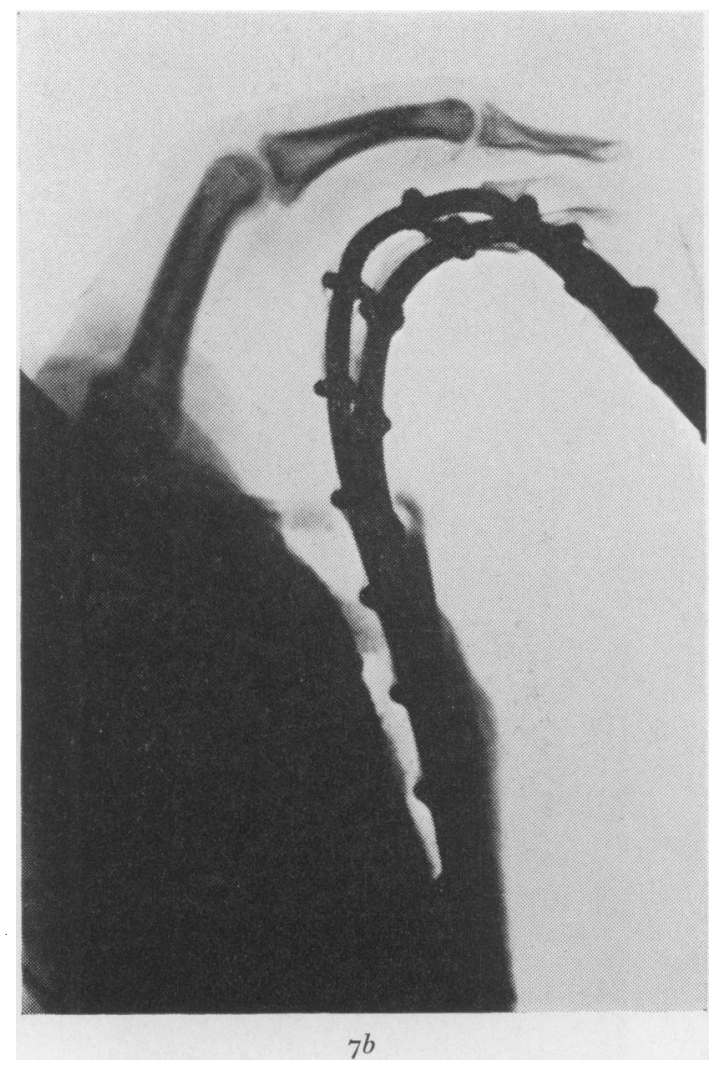

FIG. 7.-(a) Inadequate radiological evidence of reduction. (b) Deformity persists after changing the splint. $(c)$ The deformities did not cancel out.

and fixing the raw ends together. If they can be used, compression clamps are ideal. Single or crossed wires or a spike arthrodesis do not guarantee bony fusion, but a fibrous ankylosis is often stable enough (Fig. 12).

Fractures of the terminal phalanx. Fractures near the base are often open and accompanied by dislocation of the base of the nail. The wound requires careful toilet and if the nail can be replaced it acts as a useful splint, otherwise a Kirschner wire should be used. Wire is also useful for pegging a transected phalanx-end in place.

Should associated closed fractures be fixed internally? If there is only a poor prospect that the open injuries will do well, the operation should not be extended to virgin osseous territory, but if there is little risk of sepsis in the open 


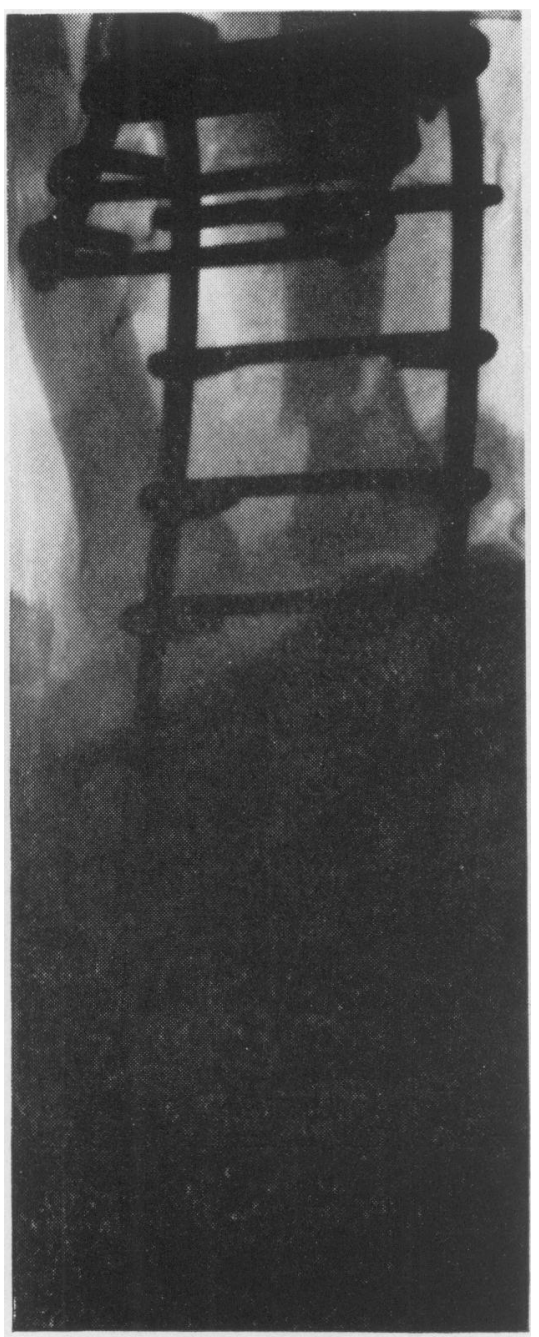

$7 b$

fractures, closed ones that would benefit from internal fixation should be treated accordingly.

A WARNING. None of these methods is particularly easy, and the successful fixing of fractures by the methods described requires the correct tools and experience in their proper use.

\section{Sepsis and Salvage}

Many open fractures in the hand carry a considerable risk of sepsis which will, from time to time, frustrate attempts at preservation. It is important, therefore, that whatever is done to conserve injured parts at the beginning should not jeopardize the uninjured part of the hand.

Superficial infection will often respond to

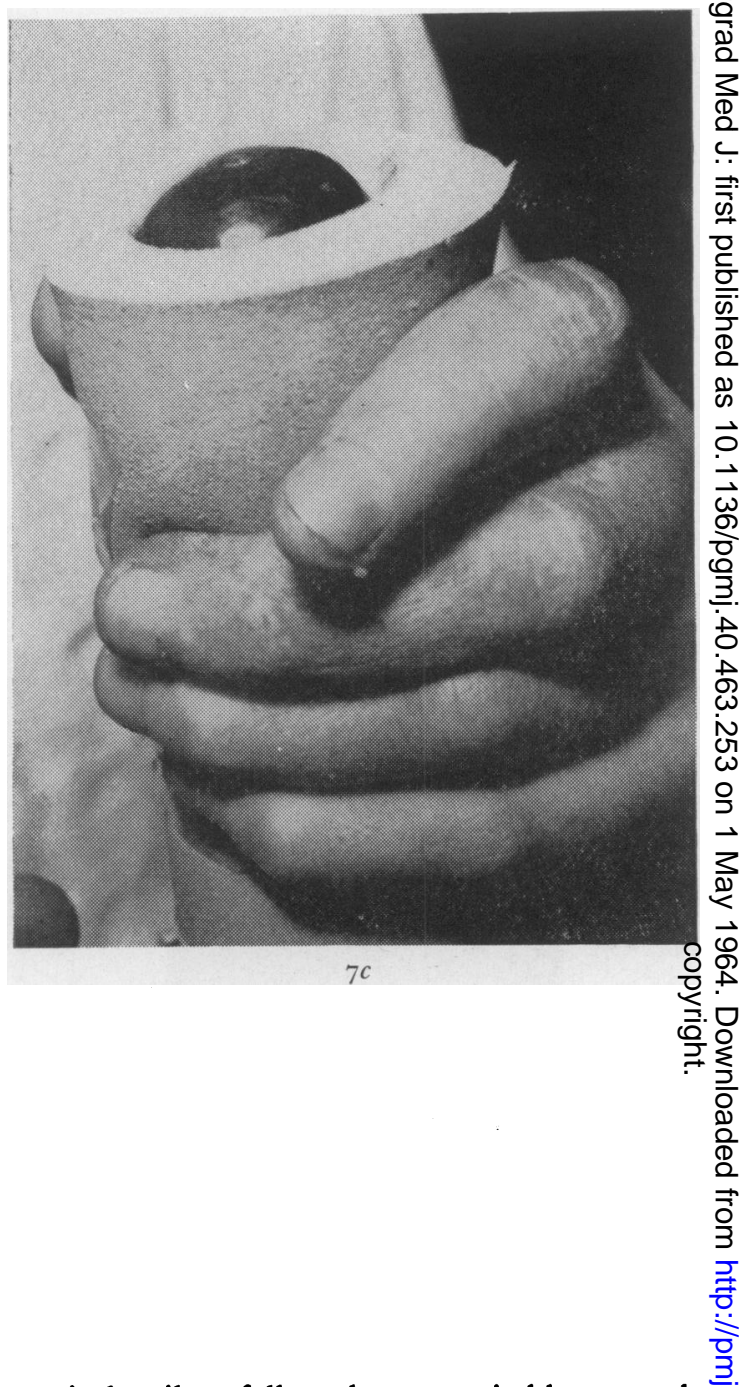

surgical toilet, followed at a suitable stage by் closure by suture, split skin, or sometimes a flap. Any antibiotics used should be chosen in the light of up-to-date bacteriological reports but if there is deep or penetrating infection, it is usuallyo necessary to sacrifice more or less of what it had been hoped to save. Free drainage is essential ato first and when local sepsis has been controlled the wound should be closed by the simplest means.

A WARNING. In many instances tissues have been devitalized by crushing and tearing and heal slowly. Stitches may need to be left in for two ore three weeks and suture lines protected by splint of bulky bandage from the sometimes disastrous conse quences of disruption by early movement.

I have to thank C. R. Wilson for his secretaria services. 


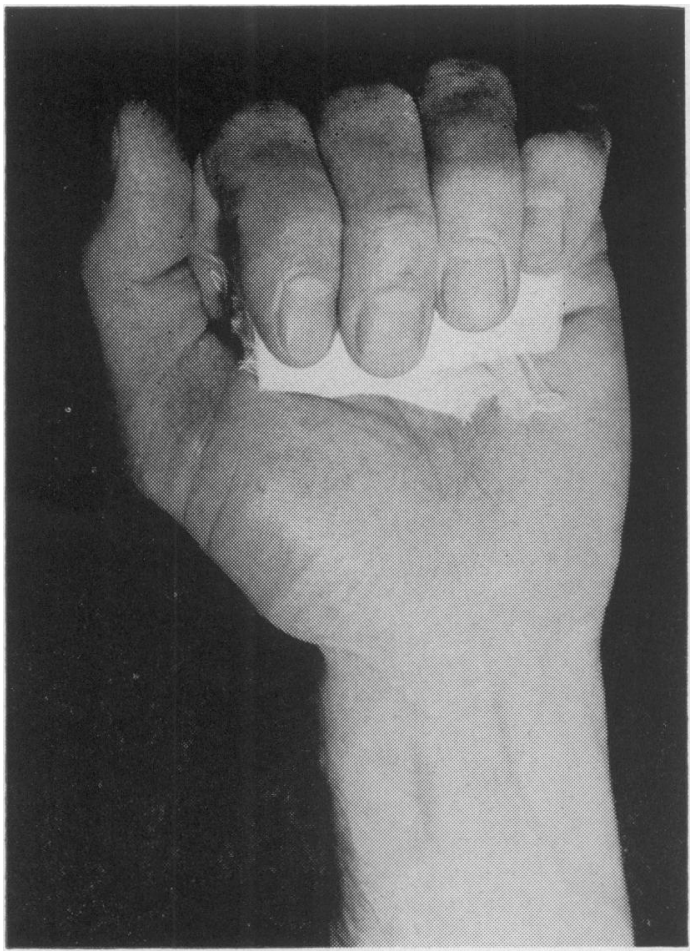

Fig. 8.-Only one digit points in the right direction.

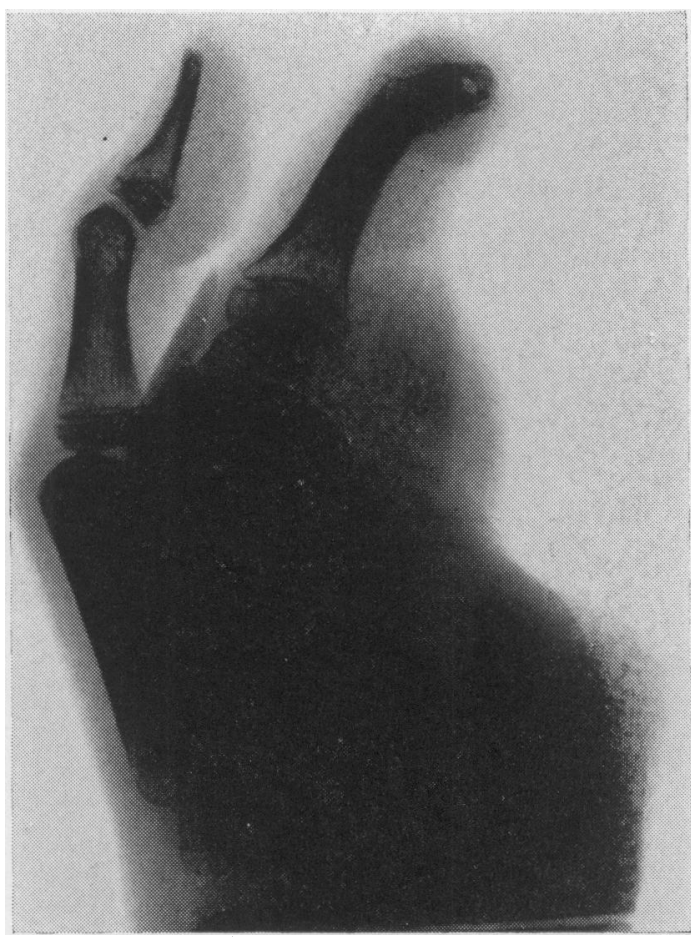
FIG. 9.-Kirschner's wire as a splint: (a) Single; $; 0$,
See also fig. 4 b.

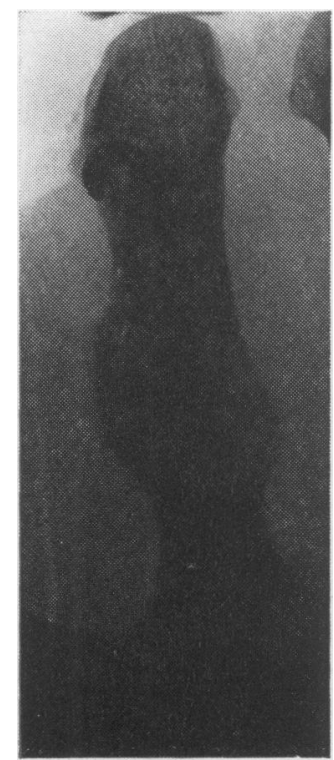

Fig. 10. - Rush's nail allowed this scaffolder to return to work in five weeks, although union took six months.

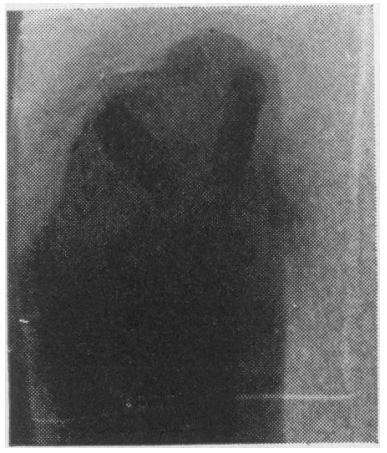

Fig. II.-The loose fragments were removed. 


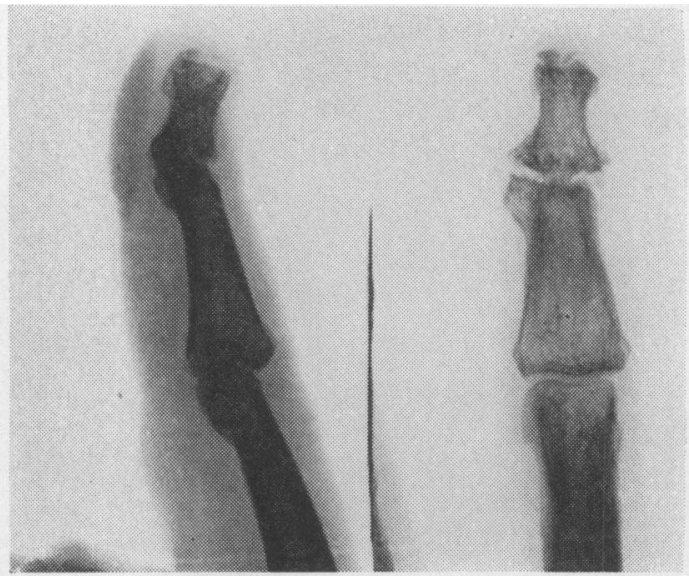

$12 b$

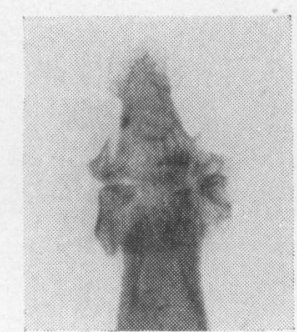

I $2 a$

Fig. 12. - Primary arthrodesis lof these shattered joints $(a, c)$ resulted in firm fibrous ankylosis $(b, d)$. This use of a wire loop is not recommended. The spike originally made on the proximal bone was absorbed. 


\section{FURTHER READING}

BaIley, D. A. (1963): 'The Infected Hand'. London: H. K. Lewis. A sound and comprehensive account of sepsis in the hand, but without special reference to 'Sepsis and Salvage'.

Clarkson, P. and Pelly, A. (1962): 'Plastic and General Surgery of the Hand'. Oxford: Blackwell. A useful work of reference and practical advice.

MAcGregor, I. A. (1962): 'Fundamental Techniques of Plastic Surgery'. London \& Edinburgh: E. \& S. Livingstone. Should be compulsory reading for all who ever have to close a wound.

RANK, B. K. and WAKefield, A. R. (I960): 'Surgery of Repair as Applied to Hand Injuries'. London \& Edinburgh: E. \& S. Livingstone. An authoritative account of the methods proved in the experience of masters of their craft.

RoBins, R. H. C. (1961): 'Injuries and Infections of the Hand'. London: Edward Arnold. Contains details of a wide range of useful techniques with proper warnings, which should be heeded, against their indiscriminative use.

Wynn-PARRY, C. B. (1958): 'Rehabilitation of the Hand'. London: Butterworths. An invaluable guide to the care of the person with a hand maimed by injury or disease.

Further Reading continued from page 265.

Koch, S. L. (1947): Immediate Care of Nerve and Tendon Injuries, Surg. Gynec. Obstet., 85, 368.

Lindsay, W. K. and Thomson, H. G. (1960): Digital Flexor Tendon; an Experimental Study. Part I, Brit. F. plast. Surg., 12, 289.

$\longrightarrow,-$, and WALkeR, F. G. (1960): Digital Flexor Tendons; an Experimental Study. Part 2, Ibid., 13, I.

LitTler, J. W. (1959): The Severed Flexor Tendon, Surg. Clin. N. Amer., 39, 435.

MAYER, L. (1938): Repair of Severed Tendons, Amer. F. Surg., 42, 714.

McCash, C. R. (196I): The Immediate Repair of Flexor Tendons, Brit. F. plast. Surg., 14, 53.

McCormack, R. M., Demuth, R. J., and Kindling, P. H. (1962): Flexor Tendon Grafts in less than Optimum Position, $\boldsymbol{f}$. Bone $\boldsymbol{F}$ t. Surg., 44A, 1360 .

Mason, M. L. (1954): Nerve and Tendon Repair of the Hand, Amer. Surg., 20, 683.

Peacock, E. E. (1959): Some Problems of Flexor Tendon Healing, Surgery, 45, 415.

Pulvertaft, R. G. (1956): Tendon Grafts for Flexor Tendon Injuries in the Fingers and Thumb, f. Bone ft $_{\text {. Surg., }}$ 38B, 175 .

VERDAN, C. E. (1960): Primary Repair of Flexor Tendons, Ibid., 42A, 647.

WAKEFIELd, A. R. (1960): The Management of Flexor Tendon Injuries, Surg. Clin. N. Amer., 40, 267. (1960): Late Flexor Tendon Grafts, Ibid., 40, 399.

White, W. L. (1960): Tendon Grafts, a Consideration of their Source, Procurement and Stability, Ibid., 40, 403. 